\title{
Analysis method for PCBs in reclaimed oil using a fast-GC triple stage quadrupole mass spectrometer with the 13-component quantitation method
}

\author{
Hiroshi Takakuwa $^{1} \cdot$ Takashi Miura $^{2} \cdot$ Toru Matsumura $^{3} \cdot$ Norie Hashi $^{3}$. \\ Michiyo Kubota $^{3}$ - Hiroshi Kutsukake ${ }^{3}$ Kazuhiro Muramatsu ${ }^{4}$. Takashi Kasamatsu ${ }^{1}$. \\ Masahiro Okuda ${ }^{1}$
}

Received: 24 May 2017 / Accepted: 19 October 2017 /Published online: 4 December 2017

(C) The Author(s) 2017. This article is an open access publication

\begin{abstract}
It is necessary for companies supplying reclaimed oil to analyze polychlorinated biphenyls (PCBs), because there is a possibility of the presence of contaminants due to trace-level PCBs in the reclaimed oil. However, common analysis methods of PCBs are time-consuming and complicated. Fast-GC triple stage quadrupole mass spectrometer with the 13-component quantitation method is an official method for analyzing PCBs in insulating oil in Japan. This method is extremely fast and simplified. The purpose of this study involves an investigation of the aforementioned fast and simple method for potential use in the analysis of reclaimed oil. Furthermore, it was attempted to combine the method with sample preparation involving only hexane dilution. The effect of sample dilutions corresponding to 100, 300, and 500 times was evaluated for reducing the matrix effect. The matrix effect was suppressed at a dilution ratio equal to or exceeding 300 times. Calibration curves of four points, namely $0.01,0.05$, 0.1 , and $0.5 \mathrm{ng} / \mathrm{mL}$, (ignored origin) by using an internal standard method were prepared for the 13 components. The square of regression coefficient $\left(\mathrm{R}^{2}\right)$ values of all calibration
\end{abstract}

Responsible editor: Philippe Garrigues

Hiroshi Takakuwa

hiroshi_takakuwa@agilent.com

1 Agilent Technologies Japan Ltd., 9-1 Takakura-Cho, Hachioji, Tokyo 192-8510, Japan

2 Kiraku Kogyo Co., Ltd., 2-7-33 Ishibeguchi, Konan, Shiga 520-3144, Japan

3 IDEA Consultants, Inc., 1334-5 Riemon, Yaizu, Shizuoka 421-0212, Japan

4 EIS Japan Co., Ltd., 1334-5 Riemon, Yaizu, Shizuoka 421-0212, Japan curves exceeded 0.997. This method was adopted for the analysis of reclaimed oil containing $0.5 \mu \mathrm{g} / \mathrm{mL}$ PCBs, which corresponds to the judgment criteria, and accurate quantitation (accuracy value, 94.0-102\%) and good repeatability (\%RSD, 3.6\%) were obtained. Furthermore, the required sensitivity was maintained even when 800 samples were analyzed without a cleaning ion source and an exchanging analysis column.

Keywords Polychlorinated biphenyls · Reclaimed oil · Fast-GC $\cdot$ Triple stage quadrupole mass spectrometer $\cdot$ Sample preparation

\section{Introduction}

In the manufacture and supply of reclaimed oil, safety and good quality of the end products is important. Suppliers of reclaimed oils collect waste lubricating oils such as engine oil, gear oil, hydraulic oil, heavy oil, and insulating oil. as raw materials, and recycle these oils at their plants. The lubricating waste oil could potentially be contaminated with trace-level poly chlorinated biphenyls (PCBs). Therefore, it is necessary for companies supplying reclaimed oil to analyze PCBs in reclaimed oil for quality control. Furthermore, an important issue involves speeding up PCB analysis to increase the production efficiency of reclaimed oil. Many studies have developed methods for the analysis of PCBs in waste oil. However, the aforementioned methods are extremely time-consuming in terms of performing a series involving sample preparation, GC measurement, and data analysis. Specifically, methods including sulfuric acid treatment, partition with dimethyl sulfoxide (DMSO)/hexane, partition with 
Table 1 List of concentrations of EC5488 (unit: ng/mL)

\begin{tabular}{|c|c|c|c|c|}
\hline IUPAC\# & CS1 & $\mathrm{CS} 2$ & $\mathrm{CS} 3$ & $\mathrm{CS} 4$ \\
\hline \multicolumn{5}{|l|}{ Native } \\
\hline 18 & 1 & 5 & 10 & 50 \\
\hline 28 & 1 & 5 & 10 & 50 \\
\hline 44 & 1 & 5 & 10 & 50 \\
\hline 52 & 1 & 5 & 10 & 50 \\
\hline 70 & 1 & 5 & 10 & 50 \\
\hline 101 & 1 & 5 & 10 & 50 \\
\hline 110 & 1 & 5 & 10 & 50 \\
\hline 118 & 1 & 5 & 10 & 50 \\
\hline 138 & 1 & 5 & 10 & 50 \\
\hline 149 & 1 & 5 & 10 & 50 \\
\hline 153 & 1 & 5 & 10 & 50 \\
\hline 180 & 1 & 5 & 10 & 50 \\
\hline 187 & 1 & 5 & 10 & 50 \\
\hline \multicolumn{5}{|c|}{ Labeled } \\
\hline 28 & 10 & 10 & 10 & 10 \\
\hline 52 & 10 & 10 & 10 & 10 \\
\hline 70 & 10 & 10 & 10 & 10 \\
\hline 101 & 10 & 10 & 10 & 10 \\
\hline 118 & 10 & 10 & 10 & 10 \\
\hline 138 & 10 & 10 & 10 & 10 \\
\hline 141 & 10 & 10 & 10 & 10 \\
\hline 153 & 10 & 10 & 10 & 10 \\
\hline 180 & 10 & 10 & 10 & 10 \\
\hline
\end{tabular}

dimethylformamide (DMF)/hexane, florisil column cleanup, and silica gel column cleanup are used in sample preparation, and the operations require skilled technologies in terms of analysis and operation time (Copland and Gohmann 1982; Orazio et al. 1989; Larsen et al. 1991; Lawn and Toffel 1987; Gordon et al. 1982; Sandra et al. 1988; Suzuki et al. 1991; Koizumi and Yoshimura 1984). Conversely, with respect to the analysis of insulation oil analysis in Japan, a few pretreatment techniques were developed to aid in performing the analysis in a more quick and easy manner (Takahashi and Honda 2010; Shimizu 2010; Hamada 2010). Furthermore, analytical methods by sample preparation with only hexane dilution were developed in gas chromatography combined with negative chemical ionization $(\mathrm{GC} / \mathrm{NCI})$ and gas chromatography combined with high resolution mass spectrometry ( $\mathrm{GC} /$ HRMS) (Takasuga et al. 2006; Machii et al. 2003). In this study, we attempted to perform an analysis by using a gas chromatography combined with triple stage quadrupole mass spectrometer (GC/MS/MS) with high selectivity involving only hexane dilution. The GC/MS/MS was selected because of its simple operability and maintainability when compared with those of GC/NCI and GC/HRMS. Additionally, the detection limit of recent GC/MS/MS is
Table 2 SRM conditions: precursor ion and product ion (unit: $\mathrm{m} / \mathrm{z}$ ) and collision energy (unit: eV)

\begin{tabular}{|c|c|c|c|}
\hline Compounds & Precursor ion & Product ion & Collision energy \\
\hline $\operatorname{TrCB}$ & 257.8 & 186 & 34 \\
\hline $\operatorname{TrCB}$ & 255.8 & 151 & 50 \\
\hline $\operatorname{TrCB}$ & 255.8 & 186 & 32 \\
\hline $\operatorname{TrCB}^{-13} \mathrm{C}_{12}$ & 269.8 & 198 & 34 \\
\hline $\operatorname{TrCB}^{-13} \mathrm{C}_{12}$ & 267.8 & 163 & 50 \\
\hline $\operatorname{TrCB}^{-13} \mathrm{C}_{12}$ & 267.8 & 198 & 32 \\
\hline $\mathrm{TeCB}$ & 291.8 & 222 & 34 \\
\hline $\mathrm{TeCB}$ & 291.8 & 220 & 34 \\
\hline $\mathrm{TeCB}$ & 291.8 & 257 & 12 \\
\hline $\mathrm{TeCB}^{-13} \mathrm{C}_{12}$ & 303.8 & 234 & 34 \\
\hline $\mathrm{TeCB}^{-13} \mathrm{C}_{12}$ & 303.8 & 232 & 34 \\
\hline $\mathrm{TeCB}^{-13} \mathrm{C}_{12}$ & 303.8 & 269 & 12 \\
\hline $\mathrm{PeCB}$ & 325.9 & 256 & 34 \\
\hline PeCB & 325.9 & 254 & 34 \\
\hline $\mathrm{PeCB}$ & 325.9 & 291 & 12 \\
\hline $\mathrm{PeCB}^{-13} \mathrm{C}_{12}$ & 337.9 & 268 & 34 \\
\hline $\mathrm{PeCB}^{-13} \mathrm{C}_{12}$ & 337.9 & 266 & 34 \\
\hline $\mathrm{PeCB}^{-13} \mathrm{C}_{12}$ & 337.9 & 303 & 12 \\
\hline НxCB & 361.7 & 290 & 30 \\
\hline НxCB & 359.8 & 290 & 35 \\
\hline $\mathrm{HxCB}$ & 359.8 & 325 & 15 \\
\hline $\mathrm{HxCB}^{-13} \mathrm{C}_{12}$ & 373.7 & 302 & 30 \\
\hline $\mathrm{HxCB}^{-13} \mathrm{C}_{12}$ & 371.8 & 302 & 35 \\
\hline $\mathrm{HxCB}^{-13} \mathrm{C}_{12}$ & 371.8 & 337 & 15 \\
\hline НрСB & 395.8 & 325.9 & 30 \\
\hline НрСВ & 393.8 & 323.9 & 35 \\
\hline НрСВ & 391.8 & 321.9 & 30 \\
\hline $\mathrm{HpCB}^{-13} \mathrm{C}_{12}$ & 407.8 & 337.9 & 30 \\
\hline $\mathrm{HpCB}^{-13} \mathrm{C}_{12}$ & 405.8 & 335.9 & 35 \\
\hline $\mathrm{HpCB}^{-13} \mathrm{C}_{12}$ & 403.8 & 333.9 & 30 \\
\hline
\end{tabular}

equivalent to that of GC/HRMS due to technological innovations, and this is also adopted in the official method for the analysis of dioxins in food by the European Union (EC 589/2014 and EC 709/2014). The selection of the analytical column is an important factor that can provide a high speed in GC analysis. Extant studies examined several columns as columns for PCB analysis (Frame 1997), and this typically corresponds to DB-5MS and HT8-PCB in Japan (Matsumura et al. 2002). However, the analysis time approximately equals or exceeds $40 \mathrm{~min}$ when these columns are used. In contrast, studies reported on high-speed analytical methods involving the use of a VF-Rapid MS PCB screen column that elute all $\mathrm{PCB}$ congeners of three Arochlors within 4 min (Cochran 2002). The column corresponds to a wide bore column fitted with a resistance column with a length of $6 \mathrm{~m}$ and an inner diameter of 
Table 3 Thirteen components used for calculation and PCB congeners contained in each component

\begin{tabular}{|c|c|c|c|c|c|c|c|c|}
\hline \multirow{2}{*}{$\begin{array}{l}\text { Type of homologue } \\
\text { TrCB }\end{array}$} & \multirow{2}{*}{$\begin{array}{l}\text { Component number } \\
1\end{array}$} & \multicolumn{7}{|c|}{ IUPAC number of major PCB congener } \\
\hline & & 17 & 18 & & & & & \\
\hline & 2 & 28 & 31 & & & & & \\
\hline \multirow[t]{3}{*}{$\mathrm{TeCB}$} & 3 & 49 & 52 & & & & & \\
\hline & 4 & 44 & & & & & & \\
\hline & 5 & 58 & 61 & 63 & 66 & 70 & 74 & 76 \\
\hline \multirow[t]{3}{*}{$\mathrm{PeCB}$} & 6 & 89 & 90 & 101 & 113 & & & \\
\hline & 7 & 85 & 110 & 120 & & & & \\
\hline & 8 & 107 & 118 & 123 & & & & \\
\hline \multirow[t]{3}{*}{$\mathrm{HxCB}$} & 9 & 139 & 140 & 147 & 149 & & & \\
\hline & 10 & 132 & 153 & 168 & & & & \\
\hline & 11 & 130 & 138 & 158 & 160 & 163 & 164 & \\
\hline \multirow[t]{2}{*}{ НрСВ } & 12 & 175 & 182 & 183 & 187 & & & \\
\hline & 13 & 172 & 180 & 191 & 193 & & & \\
\hline
\end{tabular}

$0.1 \mathrm{~mm}$ at the tip. This column was adopted in the present study. The analysis cycle time using this column approximately corresponds to $13.5 \mathrm{~min}$ including the oven cooling time. In the ordinary data analysis of PCBs, it is necessary to perform data processing on 209 congeners, and this constitutes a time-consuming process similar to that of pretreatment. Japan's insulating oil manual presents a method for quantifying the total PCB using statistical analysis based on the quantitative values of 13 components and is available online at http://www.env.go.jp/press/files/jp/ 17471.pdf (Ministry of Environment May 11, 2011). In this method, since only 13 components are the target components, it is overwhelmingly convenient when compared with the ordinary method. This method is applicable to GC/MS, GC/HRMS, and GC/MS/MS, but cannot be used with NCI. In this study, we investigate the applicability of the fast-GC triple stage quadrupole mass spectrometer with 13-component quantitation method to the analysis of reclaimed oil.

\section{Materials and methods}

\section{Regents, chemicals, and sample}

Calibration solution of PCBs: EC-5488 and internal standard solutions; EC-5379, and EC-5450 were purchased from
Cambridge Isotope Laboratories Inc. (MA, USA). The EC5488 contains reference solutions of four concentrations, namely CS $1, \mathrm{CS} 2, \mathrm{CS} 3$, and CS 4 . The concentrations of these solutions are given in Table 1 . The solutions were diluted with hexane to prepare $0.01,0.05,0.1$, and $0.5 \mathrm{ng} / \mathrm{mL}$ unlabeled PCBs congeners with $0.1 \mathrm{ng} / \mathrm{mL}$ 13C-labeled PCB congeners. The four standard solutions were used to prepare 4-point internal standard calibration curves with "ignore origin." The reclaimed oil sample in which PCBs were not detected was prepared by Kiraku Kogyo Co., Ltd. (Shiga, Japan). Kanechlor (KC) (300, 400, 500, and 600) and KC-Mix (KC-300: KC-400: KC-500: KC-600 = 1:1:1:1) for preparing reclaimed oil containing $\mathrm{PCBs}$ were purchased from GL Sciences Inc. (Tokyo, Japan).

\section{Sample preparation}

Dilution of reclaimed oil with hexane was performed for the sample preparation. An evaluation was performed as to whether sample dilutions by 100, 300, and 500 times reduce the matrix effect. The diluted solutions were prepared by adding 1,3 , and $5 \mathrm{~mL}$ of $0.1 \mathrm{ng} / \mathrm{mL}$ internal solution to $0.010 \mathrm{~g}$ reclaimed oil. The evaluation was performed by comparing the diluted solutions to internal standard solutions for peak intensities as obtained by GC/MS/MS analysis. Specifically, 13C-labeled PCB congeners (\#28, \#52, \#70, \#101, \#118, \#138, \#153, and \#180) were used as the internal

Table 4 Table of correspondence between 13 target components and 13C-labeled PCB congeners as internal standards

\begin{tabular}{lllllll}
\hline Component1 & Component2 & Component3 & Component4 & Component5 & Component6 & Component7 \\
\hline$\# 28$ & $\# 28$ & $\# 52$ & $\# 52$ & $\# 70$ & $\# 101$ & Component13 \\
Component8 & Component9 & Component10 & Component11 & Component12 & C18 \\
$\# 118$ & $\# 153$ & $\# 153$ & $\# 138$ & $\# 180$ & $\# 180$ & \\
\hline
\end{tabular}




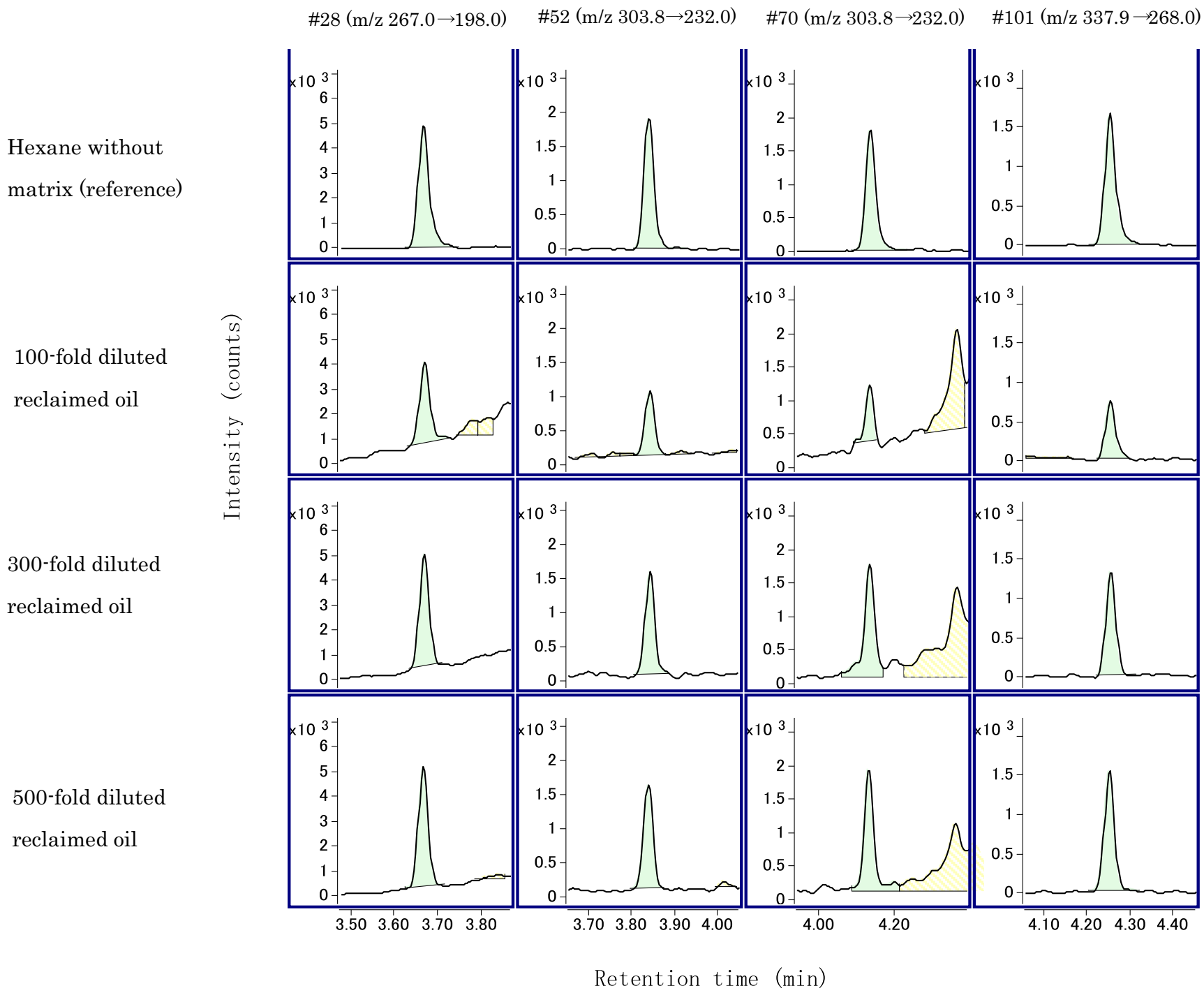

Fig. 1 SRM chromatograms of $0.1 \mathrm{ng} / \mathrm{mL}$ internal standard substances in hexane (reference) and 100, 300, and 500 times diluted reclaimed oil (\#28, 52, $70,101)$

standard (IS) to correct the sensitivity of the peaks of the 13 components. The concentration of IS in the sample was adjusted to $0.1 \mathrm{ng} / \mathrm{mL}$.

\section{GC/MS/MS analysis and quantification}

Additionally, PCB analysis was performed by GC/MS/MS (7890B GC/7010B triple quadrupole MS Agilent Technologies, USA). The samples were analyzed with a VFRapid MS PCB screen column (Agilent Technologies, USA), which corresponds to a wide bore analysis column $(10 \mathrm{~m}$, $0.53 \mathrm{~mm}, 0.25 \mu \mathrm{m})$ combined with pre-restrictor $(0.6 \mathrm{~m}$, $0.1 \mathrm{~mm}$ ) with the following temperature programs: $85^{\circ} \mathrm{C}$ for $1 \mathrm{~min}-40{ }^{\circ} \mathrm{C} / \mathrm{min}-305^{\circ} \mathrm{C}$ for $3 \mathrm{~min}$. The analysis time only corresponds to $13.5 \mathrm{~min}$ per sample including cooling oven time. The GC/MS/MS was operated in selected reaction monitoring (SRM). The SRM conditions are given in Table 2.
Quantitation of total PCB concentration by using the 13component quantitation method was conducted by using the PCBs calculation software provided by EIS Japan Co., Ltd. (Shizuoka, Japan). Table 3 shows the 13 components used for calculation and PCB congeners contained in each component. Table 4 shows the correspondence between the 13 target components and the 13C-labeled PCB congeners as internal standards.

\section{Results and discussion}

\section{Investigation of dilution rate}

Figure 1 and Figure 2 show the SRM chromatograms of $0.1 \mathrm{ng} / \mathrm{mL}$ internal standard substances in 100,300 , and 500 times diluted reclaimed oil relative to the chromatograph of 
\#28 (m/z 267.0 $\rightarrow 198.0) \quad \# 52(\mathrm{~m} / \mathrm{z} 303.8 \rightarrow 232.0) \quad \# 70(\mathrm{~m} / \mathrm{z} 303.8 \rightarrow 232.0) \quad \# 101(\mathrm{~m} / \mathrm{z} 337.9 \rightarrow 268.0)$

Hexane without

matrix (reference)

100-fold diluted reclaimed oil

300-fold diluted reclaimed oil

500-fold diluted reclaimed oil

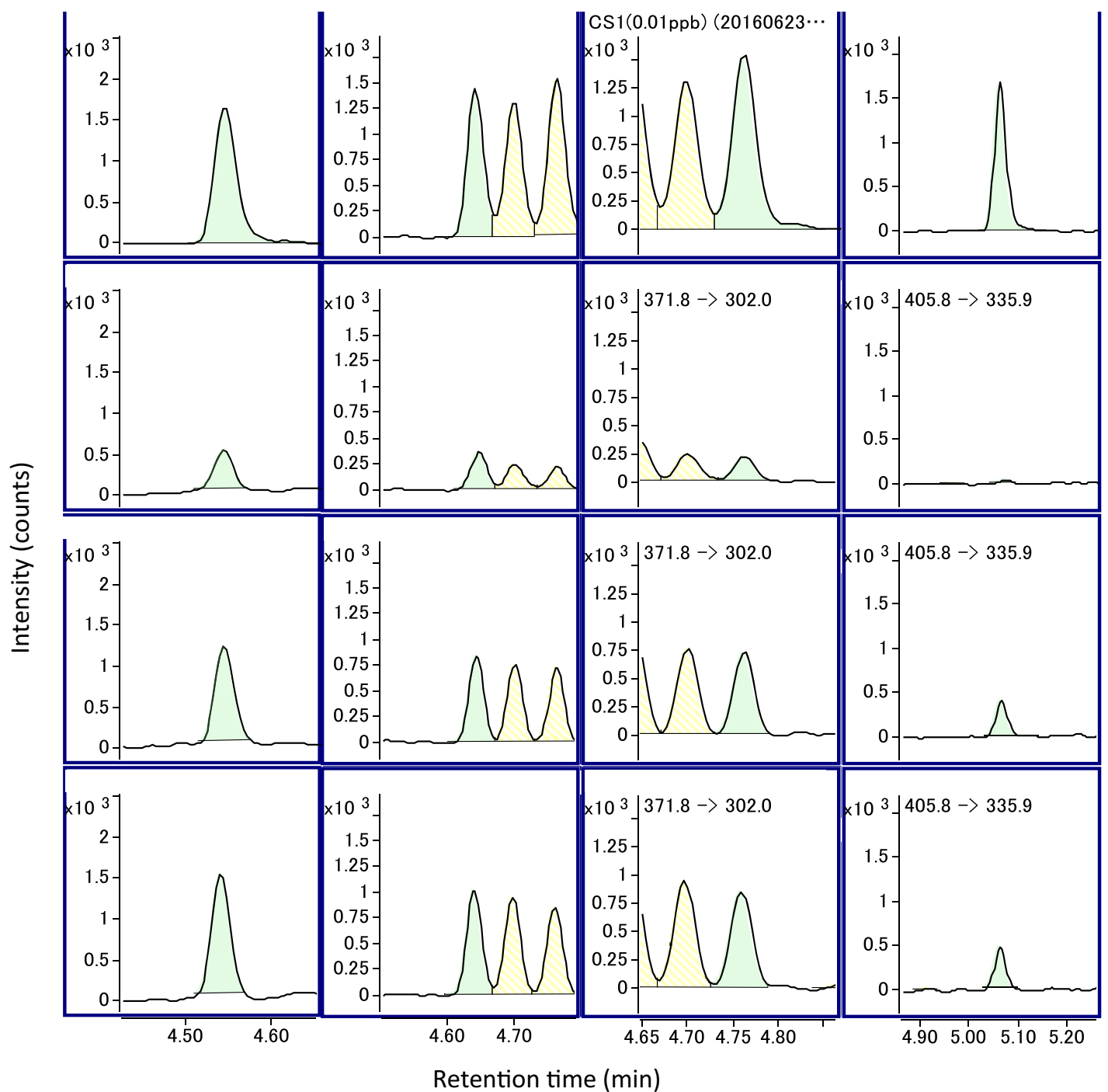

Fig. 2 SRM chromatograms of $0.1 \mathrm{ng} / \mathrm{mL}$ internal standard substances in hexane (reference) and 100, 300, and 500 times diluted reclaimed oil (\#118, $153,138,180)$

Table 5 Relative peak area values with respect to the peak area value of the hexane solution (reference) corresponding to 100

\begin{tabular}{lrrrrrrrr}
\hline & $\# 28$ & $\#$ \#2 & $\# 70$ & $\# 101$ & $\# 118$ & $\# 153$ & $\# 138$ & $\# 180$ \\
\hline 100 diluted reclaimed oil & 93.0 & 72.5 & 56.7 & 60.7 & 32.9 & 33.7 & 17.1 & 4.76
\end{tabular}

Table 6 Signal to noise ratio of the 13 components at $0.01 \mathrm{ng} / \mathrm{mL}$ and noise calculation range

\begin{tabular}{llllllll}
\hline & Component1 & Component2 & Component3 & Component4 & Component5 & Component6 & Component7 \\
\hline Signal to noise & 22.1 & 16.0 & 6.5 & 6.0 & 6.0 & 4.1 & 5.0 \\
Noise calculation range & $2.90-3.00 \mathrm{~min}$ & $2.90-3.00 \mathrm{~min}$ & $3.45-3.55 \mathrm{~min}$ & $3.45-3.55 \mathrm{~min}$ & $3.45-3.55 \mathrm{~min}$ & $3.50-3.60 \mathrm{~min}$ & $3.50-3.60 \mathrm{~min}$ \\
& Component8 & Component9 & Component10 & Component11 & Component12 & Component13 \\
Signal to noise & 6.9 & 11.8 & 8.3 & 10.3 & 9.5 & 15.5 \\
Noise calculation range & $3.50-3.60 \mathrm{~min}$ & $3.95-4.05 \mathrm{~min}$ & $3.95-4.05 \mathrm{~min}$ & $3.95-4.05 \mathrm{~min}$ & $4.00-4.10 \mathrm{~min}$ & $4.00-4.10 \mathrm{~min}$ \\
\hline
\end{tabular}


Table 7 Analytical curve equation and the square of regression coefficient $\left(\mathrm{R}^{2}\right)$

\begin{tabular}{lll}
\hline & Analytical curve equation & $\mathrm{R} 2$ \\
\hline Component1 (TrCB) & $y=0.011258 x+0.062471$ & 0.999931 \\
Component2 (TrCB) & $y=0.010924 x+0.083801$ & 0.999942 \\
Component3 (TeCB) & $y=0.009558 x+0.065022$ & 0.999710 \\
Component4 (TeCB) & $y=0.009907 x-0.077633$ & 0.997655 \\
Component5 (TeCB) & $y=0.009053 x+0.092591$ & 0.999340 \\
Component6 (PeCB) & $y=0.009509 x-0.057573$ & 0.999702 \\
Component7 (PeCB) & $y=0.006831 x+0.077679$ & 0.999794 \\
Component8 (PeCB) & $y=0.006565 x+0.054137$ & 0.999410 \\
Component9 (HxCB) & $y=0.011756 x-0.048442$ & 0.998965 \\
Component10 (HxCB) & $y=0.011713 x-0.009537$ & 0.999773 \\
Component11 (HxCB) & $y=0.007932 x+0.030521$ & 0.999812 \\
Component12 (HpCB) & $y=0.008407 x-0.019222$ & 0.999759 \\
Component13 (HpCB) & $y=0.007983 x+0.020156$ & 0.999865 \\
\hline
\end{tabular}

$0.1 \mathrm{ng} / \mathrm{mL}$ internal standard substances in the hexane solution (reference). Table 5 shows each relative peak area value of the chromatograms when the peak area value of reference is 100 . With respect to the 100 times diluted solution, the area values of the four congeners with fast retention time (\#28, \#52, \#70, and \#101) exceeded half of the reference while the area values of three congeners with slow retention time (\#118, \#153, and
\#138) corresponded to $17.1-33.7 \%$ of the reference. Furthermore, the area value of \#180 was $4.76 \%$ of the reference, and this resulted in a large decrease in strength. Conversely, with respect to the conditions involving 300 and 500 times, the area values of all congeners excluding congener \#180 exceeded half of the reference, namely $54.4-147 \%$. Furthermore, the area values of \#180 corresponded to 38 and $43.8 \%$. Hence, the influence of the matrix was suppressed at a dilution ratio equal to or exceeding 300 times. Therefore, the dilution ratio was determined as 300 times. It was thought the fact that the values of \#28, \#52,\#70,\#101, and \#118 exceeded $100 \%$ is attributed to a positive matrix effect. As widely-known, the matrix effects in GC/MS analysis are negative as well as positive due to the occurrence of ion enhancement (Coelho and Franco 2016). However, the 13C-labeled PCB congeners were used as congeners in the internal standard substance, and thus it is assumed that the ion enhancement can be corrected.

\section{Calibration curve}

The 4-point $(0.01,0.05,0.1$, and $0.5 \mathrm{ng} / \mathrm{mL})$ calibration curves with ignore origin by internal standard method were prepared for the 13 components. The 13 components at $0.01 \mathrm{ng} / \mathrm{mL}$ were detectable. The signal to noise $(\mathrm{S} / \mathrm{N})$ (peak to peak) values of each component corresponded to 4.1-22.1

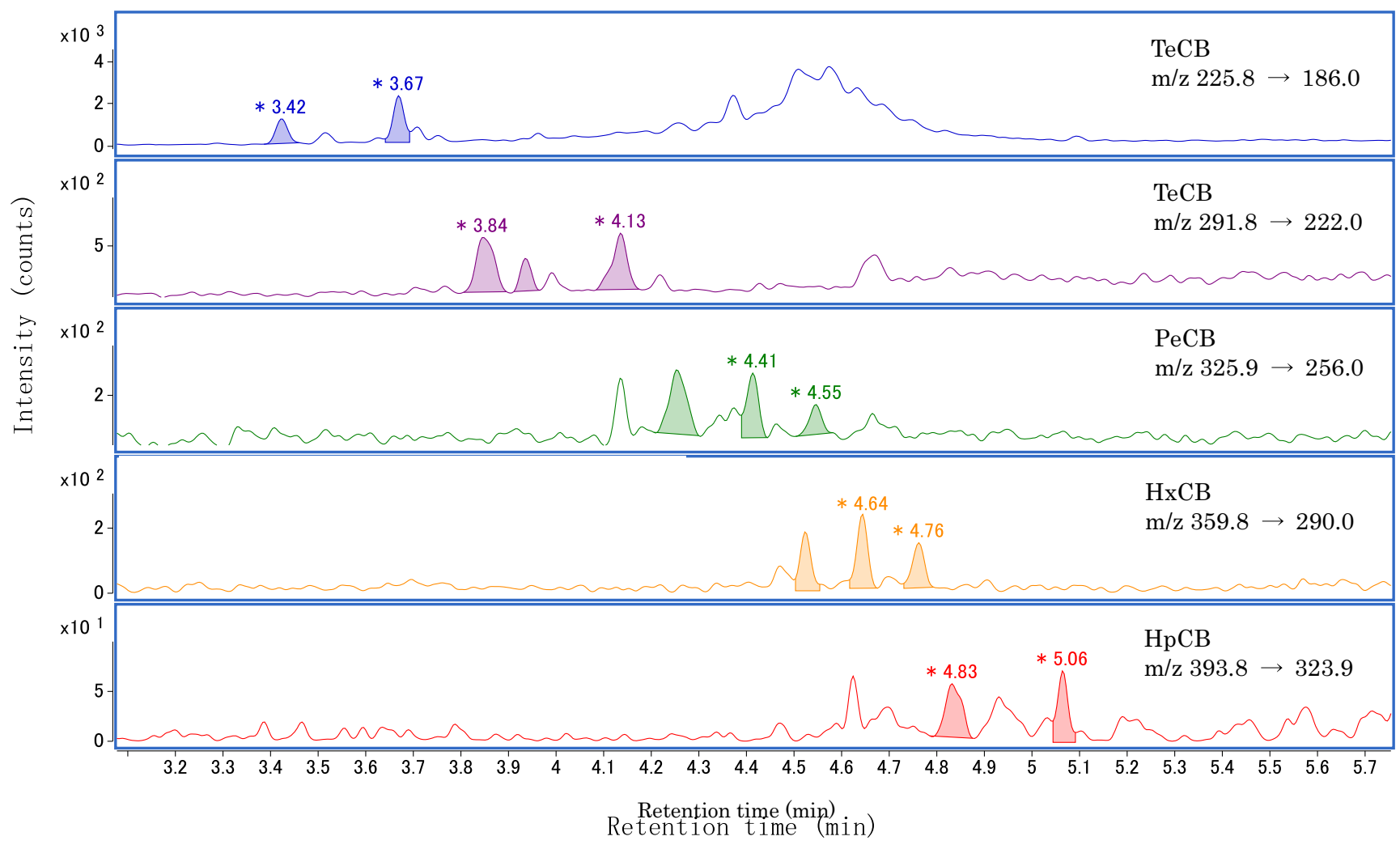

Fig. 3 SRM chromatograms of the reclaimed oil containing $0.5 \mu \mathrm{g} / \mathrm{mL} \mathrm{KC-mix}$ 
Fig. 4 Bar charts with error bars of the accuracy of total PCB concentration in reclaimed oil samples containing Kanechlor standard
Table $8 \%$ RSD of total PCB concentration in reclaimed oil containing 0.5 and $0.05 \mu \mathrm{g} / \mathrm{mL}$ KC-mix

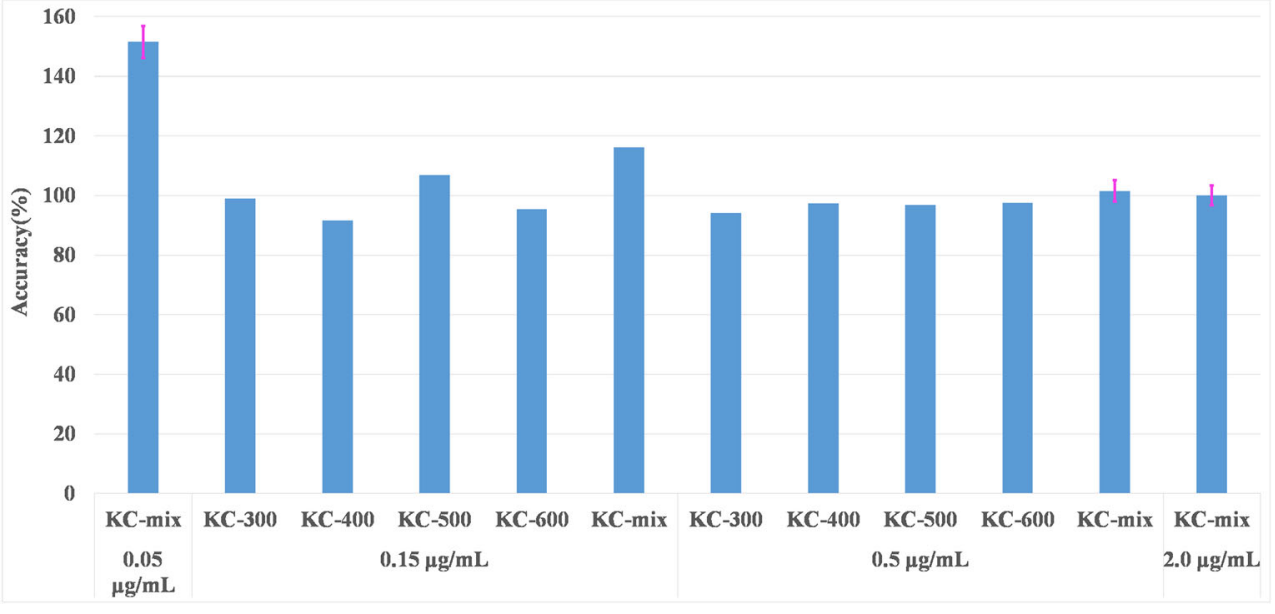

\begin{tabular}{lllllllll}
\hline & 1 & 2 & 3 & 4 & 5 & Average & SD & $\%$ RSD \\
\hline $0.5 \mu \mathrm{g} / \mathrm{mL}$ & 0.533 & 0.500 & 0.520 & 0.490 & 0.495 & 0.508 & 0.0181 & 3.6 \\
$0.05 \mu \mathrm{g} / \mathrm{mL}$ & 0.0741 & 0.0730 & 0.0818 & 0.0779 & 0.0720 & 0.0758 & 0.00408 & 5.4 \\
\hline
\end{tabular}

(Table 6). The analytical curve equation and square of regression coefficient $\left(\mathrm{R}^{2}\right)$ of the calibration curves are listed in Table 7. The $\mathrm{R}^{2}$ values of all calibration curves exceeded 0.997 .

\section{Trueness of total PCBs concentration}

Japanese regulations specify that the maximum residue limit is $0.5 \mu \mathrm{g} / \mathrm{mL}$ and that the limit of detection (LOD) in analysis

June 23, 2016

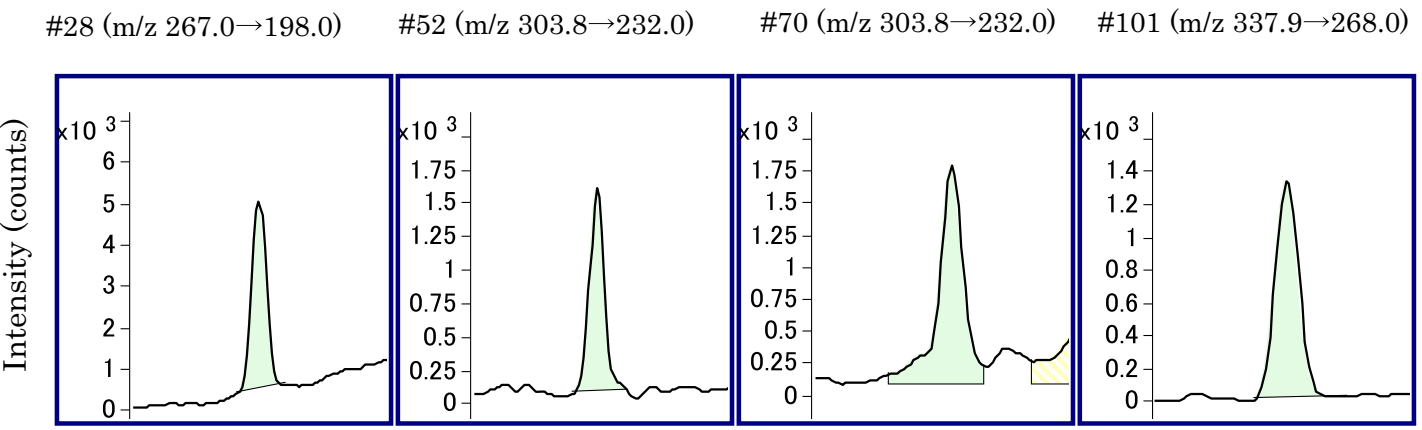

Retention time ( $\mathrm{min})$

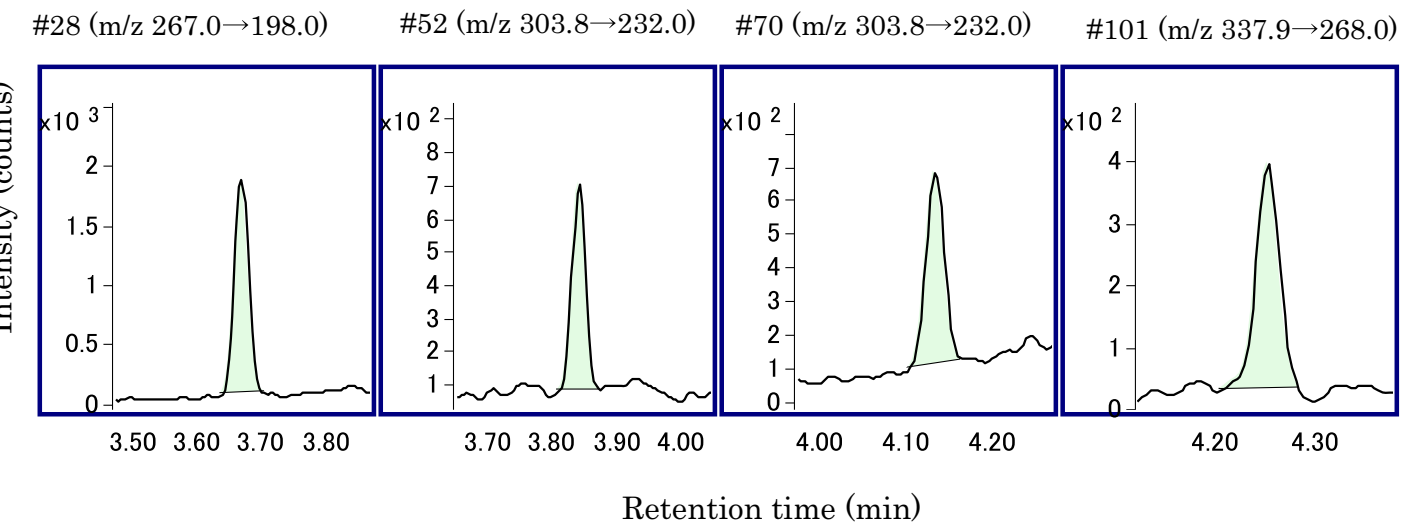

Fig. 5 Comparison of SRM chromatograms of IS on June 23, 2016 and August 30, 2016 (\#28, 52, 70, 101) 
June 23, 2016

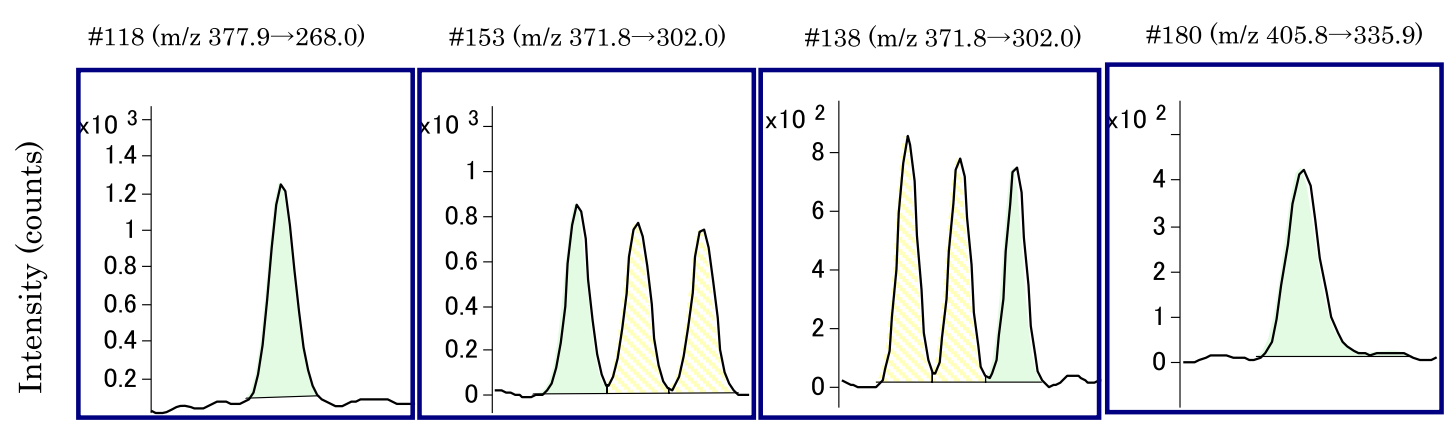

Retention time ( $\mathrm{min})$

August 30, 2016

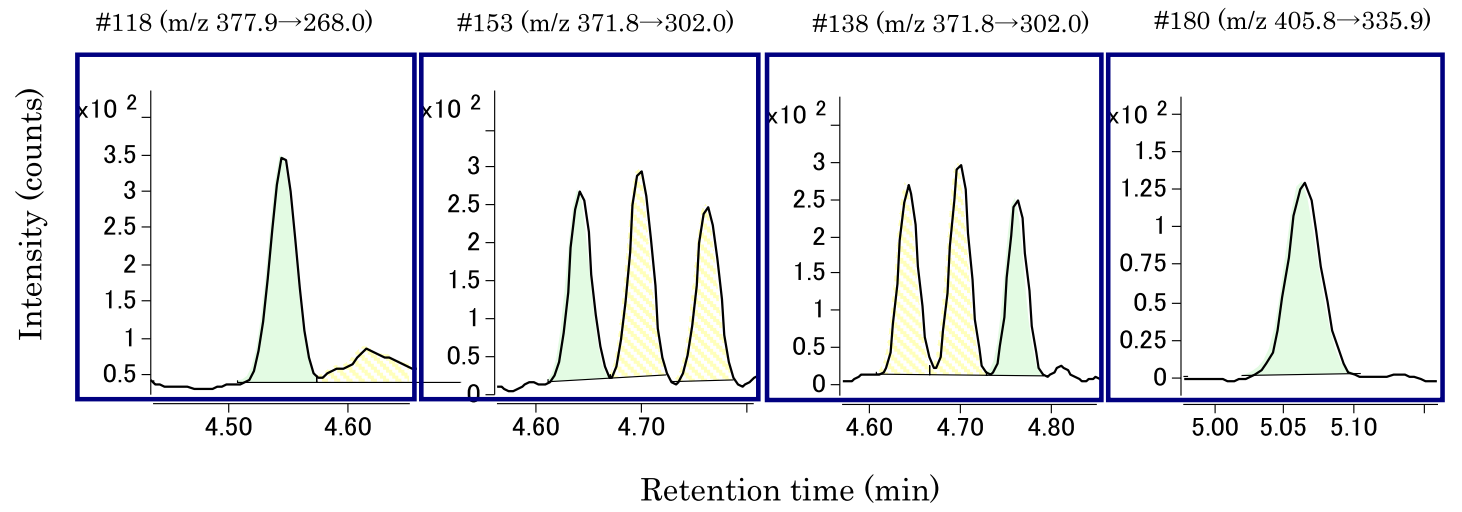

Fig. 6 Comparison of SRM chromatograms of IS on June 23, 2016 and August 30, 2016 (\#118, 153, 138, 180)

method is less than $0.15 \mu \mathrm{g} / \mathrm{mL}$. Therefore, it is necessary to correctly quantify $0.5 \mu \mathrm{g} / \mathrm{mL}$. Reclaimed oil containing 0.15 and $0.5 \mu \mathrm{g} / \mathrm{mL}$ Kanechlor standard was analyzed, and the total PCB concentration was calculated. Additionally, reclaimed oil containing lower and higher concentrations $(0.05$ and $2.0 \mu \mathrm{g} /$ $\mathrm{mL}$ ) were also analyzed. The samples of reclaimed oil containing $0.05,0.5$, and $2.0 \mu \mathrm{g} / \mathrm{mL}$ of the KC-mix were repeatedly analyzed five times. Accuracy is derived as follows: [The measured value]/[The true value] $\times 100(\%)$. The targeted 13 components were detected in all the reclaimed oil samples by adding the KC standard. Figure 3 shows the SRM chromatograms of the reclaimed oil containing $0.5 \mu \mathrm{g} / \mathrm{mL} \mathrm{KC-mix.}$ Figure 4 shows the bar chart with error bars indicating the accuracy of the total PCB concentration. The accuracy values of $0.5 \mu \mathrm{g} / \mathrm{mL}$ were $94.0-102 \%$. Additionally, the accuracy values of 0.15 and $2.0 \mu \mathrm{g} / \mathrm{mL}$ corresponded to $91.5-116 \%$ and $99.9 \%$, respectively. The results indicate that the quantification of the concentrations in the range of 0.15 to $2.0 \mu \mathrm{g} /$ $\mathrm{mL}$ was accurate. Conversely, the accuracy values of $0.05 \mu \mathrm{g} /$

Table 9 Signal to noise (S/N) (peak to peak) on June 23, 2016 and August 30, 2016, and the reduction rate

\begin{tabular}{lllllllll}
\hline & $\# 28$ & $\# 52$ & $\# 70$ & $\# 101$ & $\# 118$ & $\# 138$ & $\# 153$ & $\# 180$ \\
\hline June 23, 2016 & 67.1 & 25.7 & 29.1 & 45.2 & 40.1 & 32.5 & 37.4 & 28.0 \\
August 30, 2016 & 48.8 & 23.8 & 22.6 & 9.3 & 7.9 & 29.3 & 31.7 & 29.9 \\
Reduction rate(\%) & 73 & 93 & 78 & 21 & 20 & 90 & 85 & 107 \\
\hline
\end{tabular}

$\mathrm{mL}$ were $144-164 \%$, and this exceeded the actual concentration. However, this method can be applied sufficiently to PCB analysis in reclaimed oil given that $0.5 \mu \mathrm{g} / \mathrm{mL}$ denotes the judgment criteria.

\section{Repeatability and stability}

Table 8 shows the relative standard deviation (\%RSD) of total PCB concentration $(\mu \mathrm{g} / \mathrm{mL})$ in reclaimed oil containing 0.5 and $0.05 \mu \mathrm{g} / \mathrm{mL} \mathrm{KC-mix}$, and the \%RSD values were 3.6 and $5.4 \%$, respectively. This indicates good repeatability even at low concentrations. Figures 5 and 6 show the SRM chromatograms of IS obtained by analysis of the reclaimed oil on June 23, 2016 and on August 30, 2016, respectively. We analyzed 800 or more samples of reclaimed oils between the two analyses. During these 800 or more analyses, a cleaning ion source and an exchanging analysis column were not performed. On the other hand, an exchanging of GC liner and a tuning of quadrupole mass were performed several times. Table 9 shows the signal to noise $(\mathrm{S} / \mathrm{N})$ (peak to peak) and the reduction rate ([the $\mathrm{S} / \mathrm{N}$ of August 30,2016]/[the $\mathrm{S} / \mathrm{N}$ of June 23,2016$] \times 100(\%)$ ). The reduction rate values of \#28, $\# 52$, \#70, \#138, \#153, and \#180 correspond to 73-107\%, and the sensitivity was maintained. The reduction rate values of $\# 101$ and \#118 are 21 and 20\%, respectively. This indicates a reduction in the sensitivity of five chlorinated congeners. Thus, careful quality control is necessary with respect to the 
sensitivity of components 6,7 , and 8 that corresponds to 5 chlorinated. However, the data shown in "Calibration curve" and "Trueness of total PCBs concentration" were acquired after August 30, 2016 without cleaning ion source and exchanging analysis column. Therefore, this reveals that the proposed method was stable and maintains the required sensitivity even when 800 samples were analyzed.

\section{Conclusion}

In this study, a method to analyze PCBs in reclaimed oil was proposed by using fast-GC triple stage quadrupole MS/MS with 13-component quantitation method. The method consists of pretreating 300-fold dilution with hexane, GC/MS/MS analysis of 13.5 min per sample using VF-Rapid MS PCB screen column, and quantitative calculation with 13 components. The method was adopted for the analysis of reclaimed oil containing $0.5 \mu \mathrm{g} / \mathrm{mL}$ PCBs, and this denotes that judgment criteria including accurate quantitation (accuracy value, 94.0-102\%) and good repeatability (\%RSD, 3.6\%) were obtained. Additionally, with respect to the stability of GC/MS/ MS system, the required sensitivity was maintained even when 800 samples were analyzed without a cleaning ion source and an exchanging analysis column. These results indicate that the proposed fast and simple analysis method satisfies sensitivity, repeatability, and stability requirements.

Open Access This article is distributed under the terms of the Creative Commons Attribution 4.0 International License (http:// creativecommons.org/licenses/by/4.0/), which permits unrestricted use, distribution, and reproduction in any medium, provided you give appropriate credit to the original author(s) and the source, provide a link to the Creative Commons license, and indicate if changes were made.

\section{References}

Cochran JW (2002) Fast gas chromatography-time-of-flight mass spectrometry of polychlorinated biphenyls and other environmental contaminants. J Chromatogr Sci 40:254-268

Coelho AV, Franco C (2016) Tandem mass spectrometry-molecular characterization. InTech, Chapters published May 29, 2013 under CC BY 3.0 license. Chapter 1:3-37

Copland GB, Gohmann CS (1982) Improved method for polychlorinated biphenyl determination in complex matrices. Environ Sci Technol 16(2):121-124
Frame GM (1997) A collaborative study of 209 PCB congeners and 6 Aroclors on 20 different HRGC columns 1. Retention and coelution database. J Anal Chem 357:701-713

Gordon RJ, Szita J, Faeder EJ (1982) Determination of polychlorinated biphenyls in transformer oils by capillary gas chromatography. Anal Chem 54:478-481

Hamada T (2010) Gel permeation chromatography / multilayer silica gel column / capillary gas chromatograph / electron capture type detector (GC / ECD) method (But Japanese). J Resour Environ 46(10): 478-481 (in Japanese). https://www.amazon.co.jp/\%E8\%B3\%87\% E6\%BA\%90\%Е7\%92\%B0\%Е5\%A2\%83\%E5\%AF\%BE\% $7 \%$ $\mathrm{AD} \% 96-2010 \% \mathrm{E} 5 \% \mathrm{~B} 9 \% \mathrm{~B} 4-10 \% \mathrm{E} 6 \% 9 \mathrm{C} \% 88 \% \mathrm{E} 5 \% 8 \mathrm{~F} \% \mathrm{~B} 7-\%$ E9\%9B\%91\%E8\%AA\%8C/dp/B0043AT0AY

Koizumi T, Yoshimura H (1984) Pre-treatment of polychlorinated biphenyl analysis in mineral oils or oily waste muds. Bunseki Kagaku 34: T143-T147 (in Japanese)

Larsen B, Tilio R, Kapila S (1991) A DMSO-based cleanup procedure for determination of PCBs in waste oil. Chemosphere 23:1077-1084

Lawn RE, Toffel SA (1987) Determination of polychlorinated biphenyls in waste oil by gas-liquid chromatography. Analyst 112:53-56

Machii Y, Kumazaki O, Mizuno K, Nagano M, Hyasaka Y, Hase R, Kondo H, Deguchi T (2003) Rapid analysis of PCB in insulating oil by gas chromatography/negative ion chemical ionization mass spectrometer. J Environ Chem 13:959-971 (in Japanese)

Matsumura C, Tsurukawa M, Nakano T, Ezaki T, Ohashi M (2002) Elution orders of all 209 PCBs congeners on capillary column "HT8-PCB". J Environ Chem 12:855-865 (in Japanese)

Ministry of Environment (May 11, 2011) Simple Measurement Method Manual for Trace PCB in Insulating Oil (3rd edition). http://www. env.go.jp/press/files/jp/17471.pdf

Orazio C, Meadows J, Kapila S, Palmer C, Yanders AF (1989) Residue analysis of sediment and sewage sludge for organochlorines in the presence of elemental sulfur. Anal Chem 49:316-318

Sandra P, David F, Redant G, Denoulet B (1988) Sample preparation and CGC analysis of PCB's in waste oil. J High Resol Chromatogr Chromatogr Comm 11:840-841

Shimizu K (2010) Simple quantification method - equipment analysis method sulfuric acid treatment/divinylbenzene - methacrylate polymer column fractionation/capillary gas chromatogram/electron capture type detector $(\mathrm{GC} / \mathrm{ECD})$ method (trace PCB simple measurement - newly adopted 9 total measurement method) - (new measurement method adopted in simplified measurement method manual (2nd edition) on trace PCB in insulating oil). J Resour Environ 46:20-22 (in Japanese)

Suzuki H, Matsunaga A, Konishi F, Yanagisawa K (1991) Clean-up procedure to remove interfering substances for the determination of trace levels of polychlorinated biphenyls in electrical insulating oils. Sekiyu Gakkaishi 34:191-196 (in Japanese)

Takahashi T, Honda K (2010) Rapid analysis of PCB in electrical insulating oil by heating of multi-layer silica gel column. J Environ Chem 20:357-370 (in Japanese)

Takasuga T, Senthilkumar K, Matsumura T, Shiozaki K, Sakai S (2006) Isotope dilution analysis of polychlorinated biphenyls (PCBs) in transformer oil and global commercial PCB formulations by high resolution gas chromatography - high resolution mass spectrometry. Chemosphere 62:469-484 